\title{
QUALIDADE DA PRODUÇÃO DE BATATAS EM FUNÇÃO DA MOBILIZAÇÃO DO SOLO
}

Haroldo Carlos Fernandes ${ }^{1}$, Daniel Mariano Leite ${ }^{2}$, Lara Santana Fernandes ${ }^{3}$, Paula Cristina Natalino Rinaldi ${ }^{4}$

\section{RESUMO}

Objetivou-se com este trabalho utilizar uma plantadora de batata para operar em solo cuja superfície não havia sido revolvida (plantio direto) ou pouco revolvida (cultivo mínimo); avaliar o desempenho da cultura instalada por meio de modificações da máquina e pelo plantio convencional. O experimento foi conduzido num delineamento em blocos casualizados, com as parcelas subdivididas e quatro repetições. Pelos resultados obtidos, conclui-se que: a produção de tubérculos comerciais não foi afetada pelos tratamentos e atingiu a média de $28.266 \mathrm{~kg} \mathrm{ha}^{-1}$; sem amontoa o cultivo mínimo propiciou maior número e massa de tubérculos não comerciais; e que a amontoa, operação considerada imprescindível por alguns autores, se mostrou dispensável nas condições em que foi conduzido o experimento.

Palavras-chave: máquinas agrícolas, plantio direto, batata.

\section{ABSTRACT \\ QUALITY EVALUATION OF POTATO PRODUCTION AS A FUNCTION OF TILLAGE}

The objective of this study was to use a potato planter for operation in soils whose surface had not been plowed (no-tillage) or little plowed (minimum tillage), evaluating the performance of the installed culture by means of modifications to the machinery and conventional planting. An experiment was conducted in casual blocks was carried out with subdivided plots and four repetitions. The results showed that: the production of commercial tubers was not affected by the treatments and the average yield obtained was $28,266 \mathrm{~kg} \mathrm{ha}^{-1}$; minimum tillage (MT) resulted in the greatest number and mass of non-commercial tubers; and tilling, an operation considered essential by some authors, showed to be dispensable for the conditions in which the experiment was performed.

Keywords: agricultural machine, no-tillage, potato.

Recebido para publicação em 14/07/2011. Aprovado em 20/12/2012.

1 - Eng. Agrícola. Professor Associado. Departamento de Engenharia Agrícola / UFV - Viçosa, MG - 36570-000. haroldo@ufv.br

2. -Lic. em Ciências Agrícolas. Doutorado em Engenharia Agrícola / UFV. daniel.mariano@ufv.br

3. - Eng. de Alimentos. Mestranda em Engenharia Agrícola / UFV. Lara.fernandes@ufv.br

4. - Eng. Agrícola. Doutoranda em Engenharia Agrícola / UFV. pcrinaldi@yahoo.com.br 


\section{INTRODUÇÃO}

A batata (Solanum tuberosum L.) é um dos alimentos mais consumidos no mundo (MÜLLER et al., 2009). É uma das principais hortaliças cultivadas no Brasil, com área cultivo em torno de 200 mil ha ano ${ }^{-1}$ e produtividade média de $15 \mathrm{t} \mathrm{ha}^{-1}$ (ABAMIG, 2010).

White et al. (2009) relataram que uma amostra de $200 \mathrm{~g}$ de tubérculo fresco fornece cerca de $26 \%$ dos valores diários de referência alimentar de $\mathrm{Cu}$; $17 \%$ a $18 \%$ de $\mathrm{K}$, P e Fe; e $5 \%$ a $13 \%$ de $\mathrm{Zn}, \mathrm{Mg}$ e $\mathrm{Mn}$, destacando assim como um produto de alta qualidade para a alimentação humana.

OestadodeMinas Geraiséomaiorprodutornacional de batata, esta liderança vem sendo estabelecida devido à expansão de área cultivada e da produtividade. A bataticultura apresenta como uma importante atividade agrícola, desenvolvida por pequenos, médios e grandes produtores, além da geração de renda e empregos para uma parcela expressiva de agricultores familiares (PÁDUA et al., 2009).

Para assegurar uma emergência uniforme e devido à fragilidade do sistema radicular da cultura, Consorte (1995), salienta que o preparo do solo para a cultura da batata deve ser o mais esmerado possível, originando um leito de plantio destorroado, solto e sem camadas compactadas.

Do plantio à colheita, a cultura da batata apresenta alto grau de sensibilidade às condições de solo, sendo o seu preparo decisivo para a produtividade da cultura (BOLLER et al., 1998).

Poucos produtores estão dispostos a adotar práticas alternativas de preparo do solo para outras culturas que não sejam cereais (EKEBERG; RILEY, 1996). Estes autores conduziram, no sul da Noruega, experimento para comparar dois tratamentos de preparo do solo para batata: preparo convencional e plantio direto em restos de cevada. A produção e a qualidade dos tubérculos foram avaliadas e não foram encontradas diferenças significativas, concluindo que o plantio direto é uma alternativa viável, em comparação com o preparo convencional do solo, para a cultura da batata.

Sendo assim, objetivou-se com o presente trabalho avaliar o desempenho da cultura da batata, cultivada em diferentes sistemas de plantio como também verificar a necessidade da amontoa.

\section{MATERIAL E MÉTODOS}

O experimento foi conduzido em área do Departamento de Fitotecnia da Universidade Federal de Viçosa, MG, com altitude entre 600 e $700 \mathrm{~m}$ e declividade média de 3\%. A temperatura média anual é de $19{ }^{\circ} \mathrm{C}$, a precipitação anual está entre 1.300 e $1.400 \mathrm{~mm}$, sendo a estação chuvosa concentrada no período de outubro a março, e a umidade relativa do ar anual oscilando entre 80 a $85 \%$. A área de trabalho com aproximadamente 0,35 ha, formato retangular de $48 \mathrm{~m}$ de comprimento e $33 \mathrm{~m}$ de largura, estava em pousio há aproximadamente três anos e coberta com densa vegetação composta na quase totalidade de mucuna preta (Stylozobium aterrimum).

O solo foi classificado como Argissolo Vermelho-Amarelo Câmbico, fase Terraço (EMBRAPA, 2006), assim como a densidade do solo, a densidade de partículas e o teor de água no solo na faixa de 0,00 a $0,20 \mathrm{~m}$ de profundidade, conforme a apresentado no quadro 1 .

Os tratamentos foram definidos em função de: a) adaptações na máquina de plantio de batata, operando de três formas;

b) presença ou ausência da amontoa.

No Quadro 2, estão apresentados os tratamentos, com as respectivas descrições e operações:

As parcelas mediam $33 \mathrm{~m}$ de comprimento por 4,0 $\mathrm{m}$ de largura, nas extremidades havia um espaço de $10,0 \mathrm{~m}$ para manobras e estabilização da velocidade. As subparcelas mediam 16,5 m, correspondendo à metade de cada parcela.

Foram estudados os efeitos de sistemas de plantio (Plantio convencional, Plantio direto e Cultivo mínimo), e da prática da amontoa (ausência e presença). O experimento foi delineado em blocos casualizados (DBC), com parcelas subdivididas, sendo que nos blocos ficaram o sistema de plantio e nas sub-parcelas a prática da amontoa. Foram feitas quatro repetições.

Foi utilizado uma plantadora de batata de 2 linhas, marca Watanabe, montada ao sistema hidráulico de levante, onde na primeira adaptação efetuada na plantadora acrescentou-se uma haste escarificadora na base do sulcador e realizou-se o trabalho em solo não revolvido, conforme experimento conduzido por EKEBERG \& RILEY. (1996) (Figura 1).

\section{REVENG}

$$
\text { 115-121p. }
$$

ENGENHARIA NA AGRICULTURA, VIÇOSA - MG, V.21 N.2, MARÇO / ABRIL 2013 
Quadro 1. Propriedades e características físicas da camada do solo de 0,00 a $0,20 \mathrm{~m}$ de profundidade

\begin{tabular}{cccc}
\hline $\begin{array}{c}\text { Profundidade } \\
(\mathrm{m})\end{array}$ & $\begin{array}{c}\text { Densidade do solo } \\
\left(\mathrm{g} \mathrm{cm}^{-3}\right)\end{array}$ & $\begin{array}{c}\text { Densidade de partículas } \\
\left(\mathrm{g} \mathrm{cm}^{-3}\right)\end{array}$ & $\begin{array}{c}\text { Teor de água no solo } \\
(\% \text { em massa })\end{array}$ \\
\hline $0,00-0,10$ & 1,20 & 2,73 & 25,90 \\
$0,10-0,20$ & 1,34 & 2,94 & 26,43 \\
\hline
\end{tabular}

Quadro 2. Descrição dos tratamentos estudados

\begin{tabular}{|c|c|}
\hline Tratamento & Descrição \\
\hline PCSA & $\begin{array}{l}\text { Plantio convencional sem amontoa, executado com a plantadora na condição original, } \\
\text { sendo o solo preparado com duas passadas de enxada rotativa que operava a } 240 \text { rotações } \\
\text { por minuto no rotor com } 04 \text { facas em cada flange num total de } 24 \text { facas no eixo. A placa } \\
\text { de impacto da enxada rotativa estava abaixada; }\end{array}$ \\
\hline PCCA & Idem anterior, porém com a realização da amontoa; \\
\hline PDSA & $\begin{array}{l}\text { Plantio direto sem amontoa, executado com a plantadora adaptada conforme adaptação } 1 \text {, } \\
\text { em que os separadores de batatas receberam hastes escarificadoras, efetuado em solo que } \\
\text { teve a vegetação natural (mucuna) removida, porém não revolvido com implementos de } \\
\text { preparo do solo; }\end{array}$ \\
\hline PDCA & Idem anterior, porém com a realização da amontoa; \\
\hline CMSA & $\begin{array}{l}\text { Plantio caracterizado como cultivo mínimo sem amontoa, executado com a plantadora } \\
\text { adaptada conforme adaptação } 2 \text {, em que recebeu o conjunto de discos de grades na dianteira } \\
\text { e o sulcador tipo bota para colocação do adubo em profundidade, efetuado em solo que teve } \\
\text { a vegetação natural (mucuna) removida, porém não revolvido com implementos comuns } \\
\text { de preparo do solo e sim com os discos de grade adaptados na dianteira da plantadora. }\end{array}$ \\
\hline CMCA & Idem anterior, porém com a realização da amontoa. \\
\hline
\end{tabular}

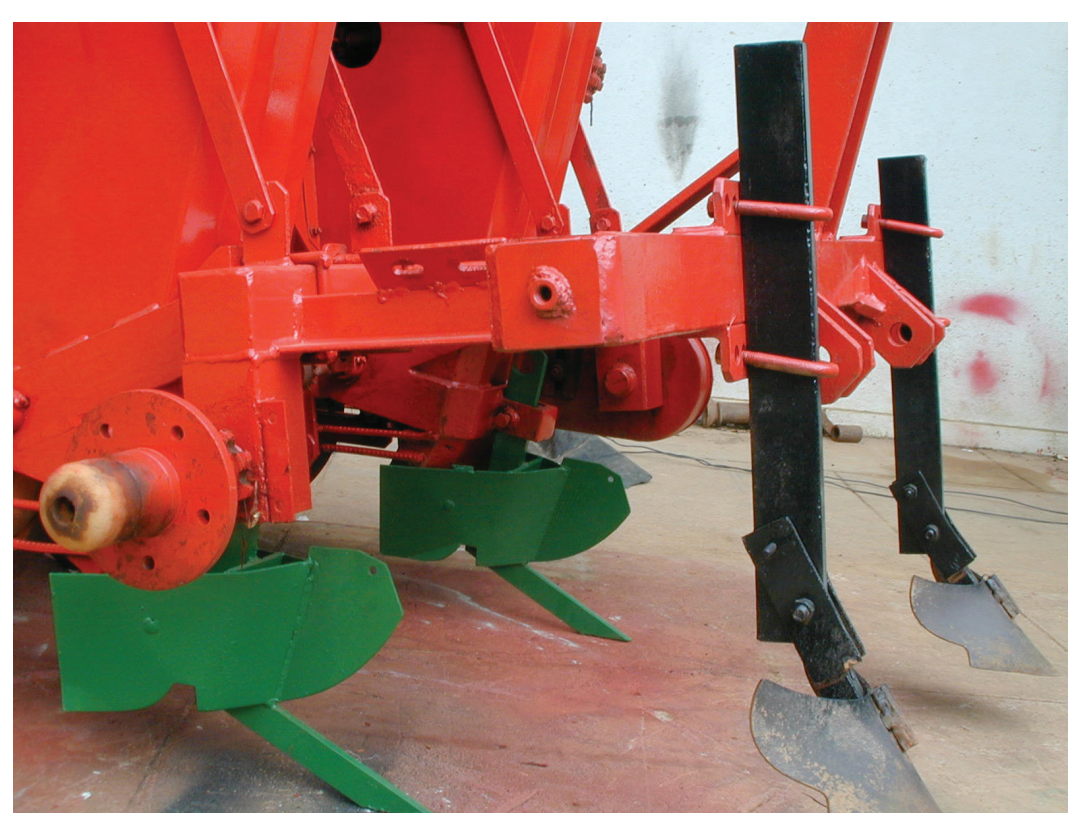

Figura 1. Vista lateral do mecanismo adaptado à plantadora, mostrando sulcador frontal, e separador do adubo com haste escarificadora. 


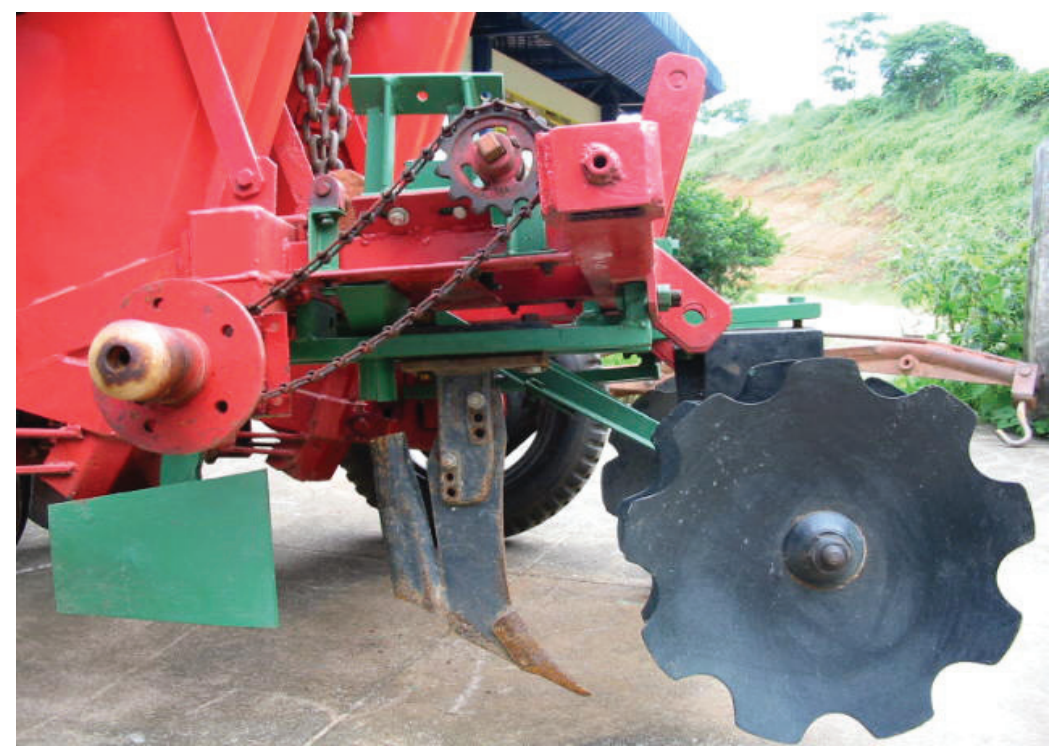

Figura 2. Vista lateral do mecanismo adaptado à plantadora, mostrando conjunto de discos de grade, sulcador tipo bota e separador de adubo.

$\mathrm{Na}$ segunda adaptação foi adaptado à plantadora um mecanismo que revolvesse o solo apenas na linha de plantio. Foram instalados dois discos de 18", de bordas recortadas, com ângulo horizontal de $15^{\circ}$ em relação à linha da barra portaferramentas, na frente de cada conjunto de plantio, tornando a plantadora um implemento multi-tarefa (policultor), conforme apresentado na Figura 2.

O plantio dos tubérculos-semente, em todos os tratamentos foi feito com o trator Massey Ferguson, modelo 275, 4x2 TDA em primeira marcha reduzida e motor a 1200 rpm. Foram utilizados tubérculos em início de brotação da cultivar Monalisa, pesando em torno de $35 \mathrm{~g}$ cada. Os tubérculos foram plantados a, aproximadamente, $0,10 \mathrm{~m}$ de profundidade à razão de quatro tubérculos $\mathrm{m}^{-1}$, com um espaçamento entre linhas de $0,75 \mathrm{~m}$.

Acolheita foi realizada com as plantas totalmente secas. Em cada subparcela foram selecionados, de forma aleatória, $5 \mathrm{~m}$ em cada uma das quatro linhas de plantio, lançando-se uma haste de bambu com a medida de $5 \mathrm{~m}$ sobre as leiras e naquele espaço as plantas foram colhidas. As plantas foram colhidas em $15 \mathrm{~m}^{2}$ de cada subparcela, totalizando $30,3 \%$ da área útil da parcela. Nas 24 subparcelas foram colhidos $1.185 \mathrm{~kg}$ de tubérculos, os quais foram utilizados nas determinações futuras.

A colheita foi realizada com enxada, separandose todos os tubérculos de cada planta para posterior contagem do número de plantas colhidas dentro da área estipulada. Após a retirada dos tubérculos do solo, os mesmos foram deixados no campo por período de três horas, suficiente para secagem da periderme e então recolhidos em sacos próprios, devidamente numerados, para posterior seleção, classificação, contagem e verificação de massa.

Em seguida os sacos foram transportados para um ambiente iluminado e iniciou-se o processo de seleção e classificação dos tubérculos, utilizandose uma balança eletrônica com precisão de $0,001 \mathrm{~kg}$ e mesa de classificação. Os tubérculos foram selecionados inicialmente em comercias e não comerciais. Dentre os comercias fez-se a classificação por tamanho de acordo com o Artigo 5 da Portaria número 307 de 27 de maio de 1977 e Lei 6.305 de 15 de dezembro de 1975 e nos não comerciais quantificou-se os tipos de defeitos ou anomalias conforme apresentado nos Quadros 3 e 4. Os valores de massa e número de tubérculos colhidos na parcela experimental foram divididos pelo número de plantas existentes na parcela para expressar a massa e o número por planta e divididos pela área para obter a produção por área.

Quadro 3. Critério de seleção dos tubérculos de acordo com o destino

\begin{tabular}{cc}
\hline Comercial & Não comercial \\
\hline \multirow{3}{*}{ Sem defeitos } & Verdes \\
& Rachados \\
& Embonecados \\
& Menores que $20 \mathrm{~mm}$ \\
\hline
\end{tabular}

\section{REVENG}

115-121p. ENGENHARIA NA AGRICULTURA, VIÇOSA - MG, V.21 N.2, MARÇO / ABRIL 2013 
Quadro 4. Classificação dos tubérculos de acordo com o tamanho

\begin{tabular}{cccc}
\hline Grande & Médio & Miúdo & Miudinho \\
\hline Mais de $45 \mathrm{~mm}$ & Entre 33 e $45 \mathrm{~mm}$ & Entre 23 e $33 \mathrm{~mm}$ & Entre 20 e 23 mm \\
\hline
\end{tabular}

\section{RESULTADOS E DISCUSSÃO}

A menor diferença entre produção total e produção comercial foi obtida no plantio convencional com amontoa (PCCA), 32.70,85 kg $\mathrm{ha}^{-1}$ e a maior diferença foi obtida no cultivo mínimo sem amontoa (CMSA), 9.379,33 $\mathrm{kg} \mathrm{ha}^{-1}$. A menor massa de tubérculos comerciais $(\mathrm{CMH})$ foi obtida no cultivo mínimo sem amontoa (CMSA) que foi de $25.996 \mathrm{~kg} \mathrm{ha}^{-1}$, valor que se encontra $84,53 \%$ acima da média nacional que é de $15.000 \mathrm{~kg} \mathrm{ha}^{-1}$ e $15,86 \%$ acima da média produzida no estado de Minas Gerais, que é de $22.437 \mathrm{~kg} \mathrm{ha}^{-1}$. A maior massa de tubérculos comerciais (CMH), que foi o obtido no plantio direto com amontoa (PDCA), de $29.879 \mathrm{~kg} \mathrm{ha}^{-1}$, ficou $99 \%$ acima da média nacional e $33,1 \%$ acima da média de produção do Estado de Minas Gerais.

Considerando a média de todos os tratamentos, o estande ficou em torno de $20 \%$ menor que o estande teórico, que seria em torno de 53.000 plantas ha ${ }^{-1}$, considerando a distância entre linhas de $0,75 \mathrm{~m}$ e a colocação de 4 tubérculos $\mathrm{m}^{-1}$. Tal redução, provavelmente, ocorreu devido à patinagem da roda motora da plantadora, às possíveis imperfeições na brotação dos tubérculos e irregularidades no mecanismo de distribuição de tubérculos da plantadora.

Os valores encontrados para massa de tubérculos comerciais (CMH) total (PTH) e estande (STD) não apresentaram diferenças significativas estatisticamente, ao nível de $5 \%$ de probabilidade pelo teste F.

As quantidades de tubérculos miúdos (M1), quantidade de tubérculos (TO) e massa de tubérculos verdes médios (PVM) produzidos sob plantio convencional (PC), plantio direto (PD) e cultivo mínimo (CM) são mostradas no Quadro 5.

O número de tubérculos miúdos produzidos por planta apresentou diferenças estatísticas para os tratamentos estudados. No cultivo mínimo (CM) foram produzidos em média 1,49 tubérculos miúdos por planta contra 1,14 tubérculos planta ${ }^{-1}$ no plantio convencional (PC) e 1,11 do plantio direto (PD). O cultivo mínimo $(\mathrm{CM})$ com a maior média de produção de tubérculos da categoria difere estatisticamente dos demais tratamentos, sendo que plantio convencional (PC) e plantio direto (PD) apresentaram médias para a referida categoria de tubérculos sem diferenças significativas estatisticamente.

Quadro 5. Número de tubérculos miúdos (M1), total (TO) e massa de tubérculos verdes médios (PVM) produzidos nos diferentes sistemas de plantio

\begin{tabular}{cccc}
\hline Tratamento $^{1}$ & $\begin{array}{c}\text { M1 } \\
\left(\text { num planta }^{-1}\right)\end{array}$ & $\begin{array}{c}\text { TO } \\
(\text { num planta }\end{array}$ & $\begin{array}{c}\text { PVM } \\
\left(\text { g planta }^{-1}\right)\end{array}$ \\
\hline PC & $1,14 \mathrm{~b}$ & $8,32 \mathrm{~b}$ & $10,96 \mathrm{a}$ \\
PD & $1,11 \mathrm{~b}$ & $9,07 \mathrm{a}$ & $14,14 \mathrm{a}$ \\
CM & $1,49 \mathrm{a}$ & $9,27 \mathrm{a}$ & $26,74 \mathrm{a}$ \\
\hline
\end{tabular}

${ }^{1}$ PC - Plantio convencional, PD - Plantio direto e CM - Cultivo mínimo. As médias seguidas de pelo menos uma mesma letra nas colunas não apresentaram diferenças significativas entre si a 5 \% de probabilidade pelo teste de Newman Keuls.

Quadro 6. Tubérculos verdes médios (PVM) produzidos nos tratamentos sem amontoa (SA) e com amontoa (CA)

\begin{tabular}{cc}
\hline Tratamento $^{1}$ & $\begin{array}{c}\text { PVM } \\
\left(\text { g planta }^{-1}\right)\end{array}$ \\
\hline SA & $21,34 \mathrm{a}$ \\
CA & $13,22 \mathrm{~b}$ \\
\hline
\end{tabular}

\footnotetext{
${ }^{1}$ SA - Sem amontoa e CA - Com amontoa. As médias seguidas de mesma letra nas colunas não diferem entre si a $5 \%$ de probabilidade pelo teste $\mathrm{F}$.
} 
No Quadro 6, são apresentados os valores obtidos para número e massa de tubérculos verdes médios (PVM) produzidos sem amontoa (SA) e com amontoa (CA). Os resultados mostraram diferenças significativas para tubérculos verdes médios (PVM) quando produzidos sem amontoa e com amontoa. Os tratamentos que não receberam a amontoa produziram em torno de $61 \%$ a mais de tubérculos verdes médios que aqueles que receberam amontoa. No entanto, tal diferença, se extrapolada para produção ha $^{-1}$, seria de aproximadamente $388 \mathrm{~kg}$, valor relativamente baixo considerando-se a produção total $\mathrm{ha}^{-1} \mathrm{de}$ tubérculos comerciais.

No Quadro 7 são apresentados os valores obtidos para massa de tubérculos não comerciais (PNC) em razão da interação entre os tratamentos. Quando se estudou o efeito da amontoa em cada sistema de plantio sobre a massa de tubérculos não comerciais produzidos por planta, os resultados mostraram que o cultivo mínimo $(\mathrm{CM})$ foi o mais afetado pela falta da amontoa (Quadro 8). Observase, assim, que a amontoa foi necessária no cultivo mínimo (CM), recomendando-se, neste caso, a amontoa, pois ela reduziu a massa de tubérculos não comercializáveis produzidos. Poderia ser dispensada, nas condições em que foi conduzido, o plantio convencional (PC) e o plantio direto (PD).

No Quadro 8 observa-se a massa de tubérculos não comerciais $(\mathrm{NCH})$ expresso $\mathrm{em} \mathrm{kg} \mathrm{ha}^{-1} \mathrm{em}$ razão da interação entre sistemas de plantio e amontoa.

No Quadro 9 são apresentados os valores relativos às massas dos tubérculos comerciais por hectare $(\mathrm{CMH})$, total por hectare $(\mathrm{PTH})$, estande obtido (STD) e porcentagem do estande teórico conseguido no experimento em cada tratamento. Os valores encontrados para massa de tubérculos comerciais $(\mathrm{CMH})$ total $(\mathrm{PTH})$ e estande (STD) não apresentaram diferenças significativas estatisticamente, ao nível de 5\% de probabilidade pelo teste $\mathrm{F}$.

Considerando os tubérculos mencionados anteriormente, a presença ou ausência da amontoa não alterou significativamente os valores encontrados. Tal fato contraria Filgueira (1999) quando postulou que a amontoa é uma prática imprescindível e aumenta a produtividade.

Quadro 7. Massa de tubérculos não comerciais (PNC) em kg planta-1 em razão da interação entre sistemas de plantio e amontoa

\begin{tabular}{cccc}
\hline & $\begin{array}{c}\mathrm{PC}^{1} \\
\left(\mathrm{~kg} \mathrm{planta}^{-1}\right)\end{array}$ & $\begin{array}{c}\text { PD } \\
\left(\mathrm{kg} \mathrm{planta}^{-1}\right)\end{array}$ & $\begin{array}{c}\mathrm{CM} \\
\left(\mathrm{kg} \mathrm{planta}^{-1}\right)\end{array}$ \\
\hline Sem amontoa $(\mathrm{SA})$ & $93,28 \mathrm{Ba}$ & $104,20 \mathrm{Ba}$ & $227,15 \mathrm{Aa}$ \\
Com amontoa $(\mathrm{CA})$ & $77,64 \mathrm{Aa}$ & $113,46 \mathrm{Aa}$ & $125,33 \mathrm{Ab}$ \\
\hline
\end{tabular}

${ }^{1}$ PC - Plantio convencional, PD - Plantio direto e CM - Cultivo mínimo. As médias seguidas de pelo menos uma mesma letra maiúscula nas linhas e minúsculas nas colunas não diferem entre si estatisticamente a $5 \%$ de probabilidade pelo teste de Newman Keuls.

Quadro 8. Massa de tubérculos não comerciais $(\mathrm{NCH})$ expresso em $\mathrm{kg} \mathrm{ha}^{-1}$, em razão da interação entre sistemas de plantio e amontoa

\begin{tabular}{lccc}
\hline & $\begin{array}{c}\mathrm{PC}^{1} \\
\left(\mathrm{~kg} \mathrm{ha}^{-1}\right)\end{array}$ & $\begin{array}{c}\mathrm{PD} \\
\left(\mathrm{kg} \mathrm{ha}^{-1}\right)\end{array}$ & $\begin{array}{c}\mathrm{CM} \\
\left(\mathrm{kg} \mathrm{ha}^{-1}\right)\end{array}$ \\
\hline Sem amontoa (AS) & $4009,83 \mathrm{Ba}$ & $4313,09 \mathrm{Ba}$ & $9379,32 \mathrm{Aa}$ \\
Com amontoa (CA) & $3270,85 \mathrm{Aa}$ & $4727,15 \mathrm{Aa}$ & $4733,82 \mathrm{Ab}$ \\
\hline
\end{tabular}

${ }^{1}$ PC - plantio convencional, PD - Plantio direto e CM - Cultivo mínimo. As médias seguidas de pelo menos uma mesma letra maiúscula nas linhas e minúsculas nas colunas não diferem entre si estatisticamente a $5 \%$ de probabilidade pelo teste de Newman Keuls. 
Quadro 9. Massa dos tubérculos comerciais (CMH), total (PTH), estande (STD) e porcentual do estande teórico obtido nos diferentes tratamentos

\begin{tabular}{|c|c|c|c|c|}
\hline Tratamento $^{1}$ & $\begin{array}{c}\mathrm{CMH} \\
\left(\mathrm{kg} \mathrm{ha}^{-1}\right)\end{array}$ & $\begin{array}{c}\text { PTH } \\
\left(\mathrm{kg} \mathrm{ha}^{-1}\right)\end{array}$ & $\begin{array}{c}\text { STD } \\
\left(\text { plantas ha }^{-1}\right)\end{array}$ & $\begin{array}{c}\% \text { do estande } \\
\text { esperado }\end{array}$ \\
\hline PCSA & $28.033,82$ & $32.043,65$ & $42.989,25$ & 80,6 \\
\hline PDSA & $30.527,03$ & $34.840,12$ & $41.989,5$ & 78,7 \\
\hline CMSA & $25.995,99$ & $35.375,32$ & $41.656,25$ & 78,1 \\
\hline PCCA & $27.482,29$ & $30.753,14$ & $42.489,38$ & 79,7 \\
\hline PDCA & $29.879,19$ & $34.606,34$ & $41.656,25$ & 78,1 \\
\hline CMCA & $27.679,68$ & $31.888,63$ & $41.096,87$ & 77,1 \\
\hline
\end{tabular}

${ }^{1}$ PCSA - Plantio convencional sem amontoa, PDSA - Plantio direto sem amontoa, CMSA - Cultivo mínimo sem amontoa, PCCA Plantio convencional com amontoa, PDCA - Plantio direto com amontoa e CMCA - Cultivo mínimo com amontoa.

\section{CONCLUSÕES}

- A produção de tubérculos comerciais não foi afetada pelos tratamentos e atingiu a média de $28.266 \mathrm{~kg} \mathrm{ha}^{-1}$;

- Sem a amontoa o cultivo mínimo (CM) propiciou maior número e massa de tubérculos não comerciais;

- A adaptação da máquina não constitui tarefa difícil e onerosa, sendo possível sua realização em qualquer propriedade que disponha de pequena oficina;

\section{REFERÊNCIAS BIBLIOGRÁFICAS}

ABAMIG-ASSOCIAÇÃODOSBATATICULTORES DO ESTADO DE MINAS GERAIS Órgão Informativo da ABAMIG. 9, n.2. 2010

BOLLER, W., PREDIGER, A.J., KLASSMANN, V. Sistemas de preparo do solo para a implantação da cultura da batata (Solanum tuberosum L.). In: Congresso Brasileiro de Engenharia Agrícola, Poços de Caldas: Anais..., Sociedade Brasileira de Engenharia Agrícola. p. 75-177. 1998

CONSORTE, J.E. Implantação da cultura da batata. In: BRINHOLI, O. Cultura da batata. (Solanum tuberosum sp tuberosum). Botucatu: FCA/UNESP, 2, p.284-337. 1995.
EKEBERG, E.; RILEY, H.C.F. Effects of mouldboard ploughing and dicect planting on yield and nutrient uptake of potatoes in Norway. Nespa Hedmark, Norway. Soil \& Tillage Research, v.39, p.131-142, 1996.

EMBRAPA. CNPS Sistema brasileiro de classificação de solos. Brasília: Embrapa. Produção de Informação: Rio de Janeiro: Embrapa Solos. 306p. 2006.

FILGUEIRA, F.A.R. Práticas culturais adequadas em bataticultura. Informe Agropecuário, v.20, n.197, p.34-41, 1999.

MULLER, D.R. BISOGNIN, D.A.; ANDRIOLO, J.L.; MORIN JÚNIOR, G.R.; GNOCATO, F.S. Expressão dos caracteres e seleção de clones de batata nas condições de cultivo de primavera e outono. Ciência Rural, v.39, n.05, p.1327-1334, 2009.

PÁDUA, J.G.; MESQUITA, H.A.; CARMO, E.L.; DUARTE, H.S.; DIAS, J.P.T.; DUARTE FILHO, J. Potencial produtivo de cultivares francesas de batata para o estado de Minas Gerais. Revista Trópica - Ciências Agrárias e Biológicas. v.3, n.2, p.73-78, 2009.

WHITE, P.J.; BRADSHAW, J.E.; DALE, M.F.B.; RAMSAY, G.; HAMMOND, J.P. e BROADLEY, M.R. Relationships between yield and mineral concentrations in potato tubers. HortScience, v.44, p.6-11, 2009. 